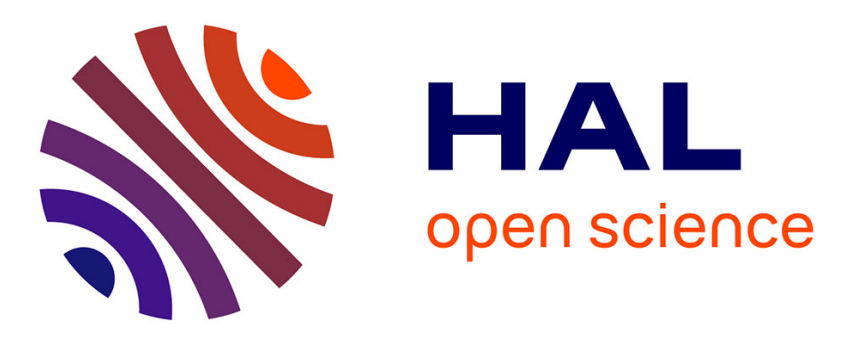

\title{
Electro-thermal measurements and finite element method simulations of a spark plasma sintering device
}

Anthony Pavia, Lise Durand, François Ajustron, Vincent Bley, Geoffroy

Chevallier, Alain Peigney, Claude Estournès

\section{- To cite this version:}

Anthony Pavia, Lise Durand, François Ajustron, Vincent Bley, Geoffroy Chevallier, et al.. Electro-thermal measurements and finite element method simulations of a spark plasma sintering device. Journal of Materials Processing Technology, 2013, vol. 213, pp. 1327-1336. 10.1016/j.jmatprotec.2013.02.003 . hal-00905512

\section{HAL Id: hal-00905512 \\ https://hal.science/hal-00905512}

Submitted on 18 Nov 2013

HAL is a multi-disciplinary open access archive for the deposit and dissemination of scientific research documents, whether they are published or not. The documents may come from teaching and research institutions in France or abroad, or from public or private research centers.
L'archive ouverte pluridisciplinaire HAL, est destinée au dépôt et à la diffusion de documents scientifiques de niveau recherche, publiés ou non, émanant des établissements d'enseignement et de recherche français ou étrangers, des laboratoires publics ou privés. 


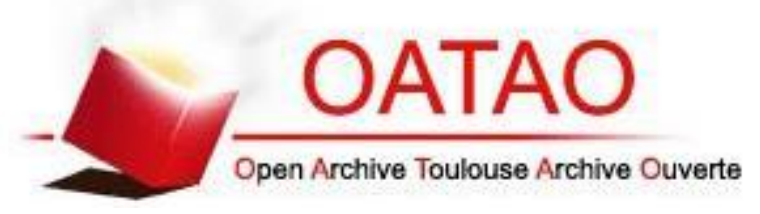

\section{Open Archive TOULOUSE Archive Ouverte (OATAO)}

OATAO is an open access repository that collects the work of Toulouse researchers and makes it freely available over the web where possible.

This is an author-deposited version published in : http://oatao.univ-toulouse.fr/ Eprints ID : 9370

To link to this article : DOI:10.1016/j.jmatprotec.2013.02.003

URL : http://dx.doi.org/10.1016/j.jmatprotec.2013.02.003

To cite this version : Pavia, Anthony and Durand, Lise and Ajustron, François and Bley, Vincent and Chevallier, Geoffroy and Peigney, Alain and Estournès, Claude Electro-thermal measurements and finite element method simulations of a spark plasma sintering device. (2013) Journal of Materials Processing Technology, vol. 213 ( ${ }^{\circ}$ 8). pp. 13271336. ISSN 0924-0136

Any correspondance concerning this service should be sent to the repository administrator: $\underline{\text { staff-oatao@ listes-diff.inp-toulouse.fr }}$ 


\title{
Electro-thermal measurements and finite element method simulations of a spark plasma sintering device
}

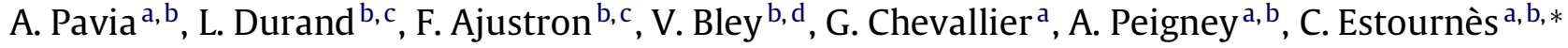 \\ a CNRS, Institute Carnot Cirimat, F-31602 Toulouse cedex 9, France \\ b Université de Toulouse, Institut Carnot CIRIMAT, UPS CNRS, Université Paul-Sabatier, 31062 Toulouse cedex 9, France \\ ${ }^{c}$ CNRS - CEMES (Centre d'Elaboration de Matériaux et d'Etudes Structurales), Toulouse, France \\ d LAPLACE, Toulouse, France
}

Keywords:

SPS

Thermal and electrical measurement

Modeling, FEM

\begin{abstract}
a b s t r a c t
Current, voltage and temperature measurements were performed at different points of the system to identify the controlling parameters of the spark plasma sintering (SPS) process. The very low inductance effects despite the high intensity current circulating through the SPS column justifies the use of Joule heating to characterize the phenomenon. The measurements also enabled the improvement and validation of an earlier electro-thermal numerical model developed using the finite element method (FEM). It has been shown that the electrical resistivity and the thermal conductivity of each of the elements are crucial parameters for the simulations. These parameters strongly modify the current modeled, thereby affecting the temperature distribution throughout the SPS column.
\end{abstract}

\section{Introduction}

SPS (Spark Plasma Sintering) which consists of heating by applying a pulsed direct current through the die, and sometimes through the sample, while applying a uniaxial pressure allows high consolidation and densification rates with negligible grain growth (Chaim et al., 2008). But, many questions still remain concerning both the mechanisms involved and the electrical and thermal behavior of the tools during the SPS cycles. In particular few studies have been performed on the influence of the pulse sequences of the current generated by the SPS machines on the temperature distribution in the tools. Cincotti et al. (2007) developed electrical instrumentation on a 515S SPS apparatus (Sumitomo Heavy Industries Ltd., Kanagawa, Japan) to measure the current and voltage with a high sampling frequency. They determined the root mean square values (RMS) of this recording in order to simulate the distributions of temperature, current and strain in the SPS graphite stack containing no sample. Several measurements and models highlight the presence of temperature gradients depending on the electrical properties (conductivity) of the samples to be sintered. Wang et al. (2010) also carried out a FEM simulation of temperature and stress distributions in an SPS Stack containing an insulating sample (i.e.: alumina). Their FEM analysis includes a self-defined Proportional-Integral-Differential (PID) Module which is able to

\footnotetext{
* Corresponding author at: CIRIMAT 118, route de Narbonne 31062, Toulouse, France. Tel.: +33 561556109; fax: +33 561556163.

E-mail address: estournes@chimie.ups-tlse.fr (C. Estournès).
}

control the temperature and heating rates along the SPS cycle. Munoz and Anselmi-Tamburini (2010) also used a simulation code that includes a PID Module to compare the modeled temperature and stress field distributions in the SPS stack containing either a conducting material (copper) or an insulating material (alumina). A common view of these authors is that current distribution is an important factor in the distribution of temperatures within the equipment. The determination of the RMS values of the voltage ( $U_{R M S}$ ) across and the current ( $I_{R M S}$ ) passing through the SPS tools, the latter being responsible for its heating by Joule effect, is essential to evaluate the thermal gradients in the SPS column.

In this study a specific instrumentation has been developed to perform simultaneous temperature measurements at several points of the SPS column and electrical measurements across it, giving real time thermal and electrical conditions of the stack during the overall sintering cycle the (Fig. 1). Then, the different values collected were used as input data to an SPS numerical model of electro-thermal coupling already developed by some of the authors: Molénat et al.(2010). Finally, the model was improved with the results obtained.

\section{Electrical and thermal measurements}

\subsection{Experimental}

2.1.1. Electrical measurements: measurements of the RMS values

In usual SPS machines, the input source to heat the tools is a pulsed direct current for which the waveform pattern can vary. 


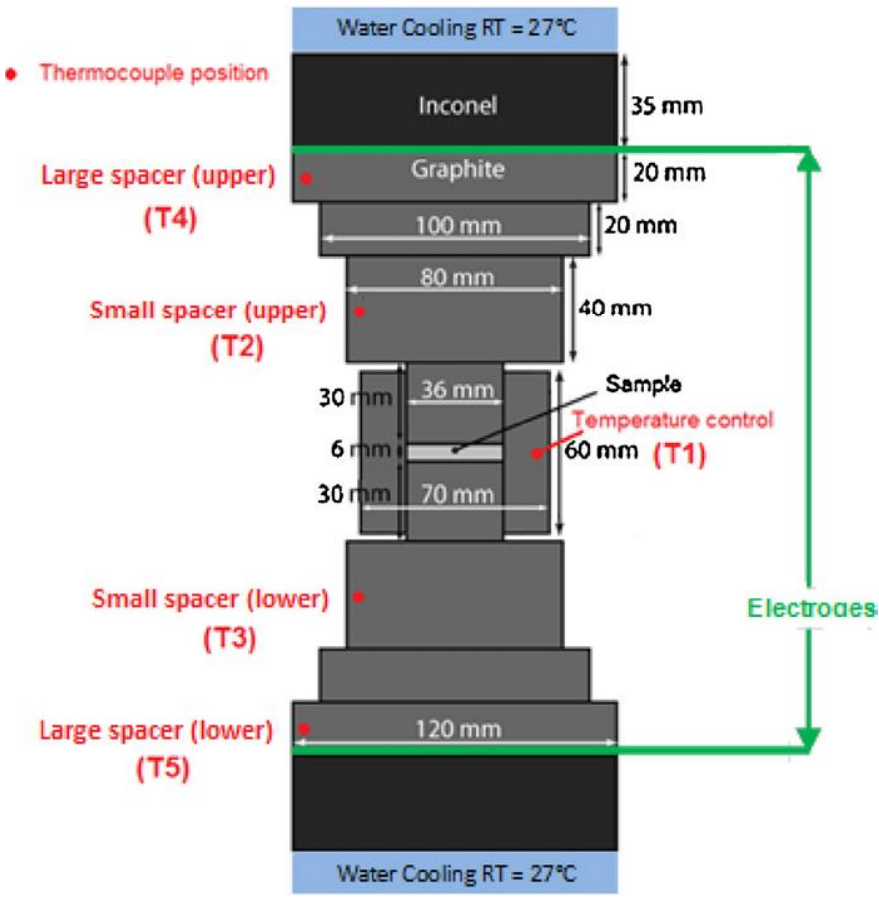

Fig. 1. Diagram of the SPS: dimensions of each element, position of thermocouples and water cooling.

Industrial SPS devices are equipped with current and voltage sensors which provide average values (of the magneto-electric type) all along the sintering cycles. These data are crucial to determining the power injected into the device for resistive heating. This electrical power $\mathrm{P}$ dissipated in a heater of resistance $\mathrm{R}$ and transformed into heat is expressed by Joule's law (1):

$\mathrm{P}=\frac{1}{\mathrm{~T}} \int_{\mathrm{t}}^{\mathrm{t}} \mathrm{u}(\tau) \mathrm{i}(\tau) d \tau=\frac{\mathrm{R}}{\mathrm{T}} \int_{\mathrm{t}}^{\mathrm{t}} \mathrm{i}^{2}(\tau) d \tau$

where $\mathrm{u}$ and $\mathrm{i}$ are the instantaneous voltage and current applied to the sample and $\mathrm{T}$ the $\mathrm{AC}$ period.

This relation is valid for direct currents (voltages) (without an AC component) as well as alternative currents (voltages) but in this later case $U$ and I represent the RMS values. In addition, this relation is no longer valid if the circuit contains a reactive component, the dipole considered should be purely resistive. In most SPS devices, the current delivered is not a pure DC current an alternating component is present, so the common configuration (12 current pulses and two timeouts), is a quasi-periodic pulsed DC current. To allow power modulation, the three-phase full-wave rectification pulses were individually controlled by delaying the initiation of the silicon-controlled rectifier(SCR). The pulse characteristics were variable depending on the power required by the PID temperature controller to satisfy the set-point temperature. So, the current was not sinusoidal, the RMS current and voltage should be calculated for a whole number of periods. The relationship to obtain the RMS voltage is of the form (2):

$\mathrm{U}_{\mathrm{RMS}}=\sqrt{\frac{1}{\mathrm{~T}} \int_{\mathrm{t}}^{\mathrm{t}} \mathrm{u}^{2}(\tau) d \tau}$

The RMS intensity of the current is given by a similar expression. Thus, to evaluate the power dissipated in the heating tools, the RMS values of the voltage and the intensity of the current should be determined. To do so, specific instrumentation was developed.

When confronted with a pulsed current, instantaneous magnitudes of $u(t)$ and $i(t)$ must be recorded to calculate their RMS values. To do so, sensors were selected for sampling the signals $(\mathrm{u}(\mathrm{t})$ across the column and $\mathrm{i}(\mathrm{t})$ passing through) with a sufficiently high frequency (up to $10,000 \mathrm{~Hz}$ ) to describe each pulse correctly. The intensity of current delivered by the SPS machine (SPS Syntex Inc., model 2080) used in this study can be as high as 8000A. For security reasons and accuracy of the measurements, it is important to not modify this high power circuit and to achieve current measurements without contact. Ray and Davis (1999) have shown that a wide band Rogowski coil sensor (Power Electronic Measurements, CWT60) can be used for measuring current at high frequency bandwidths up to $7 \mathrm{MHz}$. Ray (1999) stated that this probe also allows the measurement of high level pulsed currents. However, one of the limits of this type of sensor is that it is not able to measure the DC component of a current, which corresponds to its average value. Therefore, using this type of sensor, the DC component of the signal should be restored prior to the calculation of its average and effective values. Fortunately, this becomes possible by correcting it from the values measured at the dead times where it should be null. From the instantaneous voltage and intensity measurements, average and RMS values are calculated using a Labview routine (National Instrument software). The signal was also calibrated using an oscilloscope to verify the correspondence between measured and calculated mean values. To measure the voltage across the SPS column, the potential was considered uniform over the entire contact surface. To improve the voltage measurement accuracy, stainless steel electrodes were designed to be placed directly between the large upper graphite spacer and the Inconel part (Fig. 1). These electrodes were linked to a differential input of the NI Compact DaQ system.

\subsubsection{Temperature measurements}

A set-up equipped with $8 \mathrm{~K}$-type thermocouples was also developed in order to perform temperature measurements at several points of the column at the same time as electric data acquisition. The data collected were synchronized with the electrical measurements using a Labview routine. The data files thus generated were used to feed the model developed or to validate it. The thermocouple positions are indicated in Fig. 1; T1 control temperature at the surface of the graphite die, T2 and T3 (upper and lower respectively) temperatures on the small spacers, T4 and T5 (upper and lower respectively) temperatures on the large spacers.

\subsubsection{Standard SPS experiments}

To achieve electro-thermal modeling of the SPS system as faithfully as possible while limiting approximations, standard experiments have been defined. These SPS manipulations were performed on graphite dies of $36 \mathrm{~mm}$ inner diameter and on conducting (manganese) and non-conducting (alumina) samples of $6 \mathrm{~mm}$ thickness. The samples were previously compacted to get rid of any changes in their densities because porosity has a strong influence on their physical properties. An experiment without a sample (graphite against graphite) was also conducted. The thermal cycle studied consisted of a rise in temperature at $100{ }^{\circ} \mathrm{C} / \mathrm{min}$ up to $900^{\circ} \mathrm{C}$ with a dwell time of $5 \mathrm{~min}$ at this temperature. A pressure of $100 \mathrm{MPa}$ is applied from room temperature to minimize the electrical contact resistances.

\subsection{Results and discussions}

From the thermal data, when comparing the temperature measurements of the upper and lower large spacers, that the graphite parts located below the matrix were found warmer than that located above. Even if the column seems to be geometrically symmetrical, it does not seem to be in terms of heat transfer. This may be due to the non-symmetry of heat loss by radiation, but more likely to the non-symmetry of heat loss through conducto-convection at 
a)

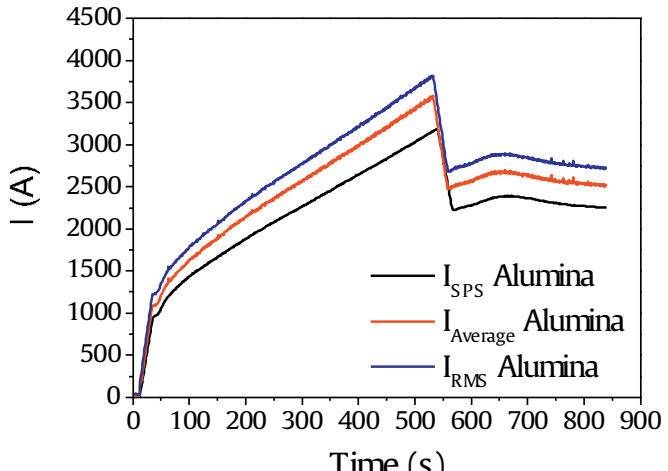

b)

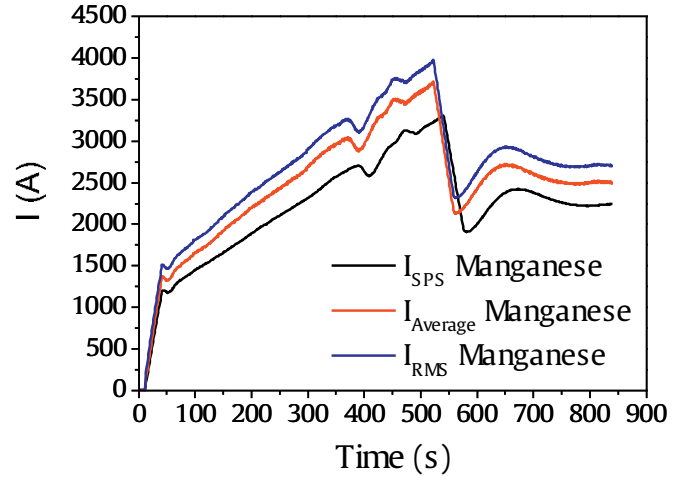

c)

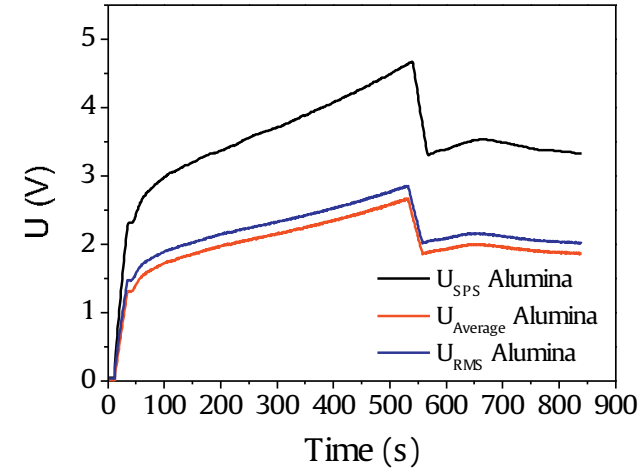

d)

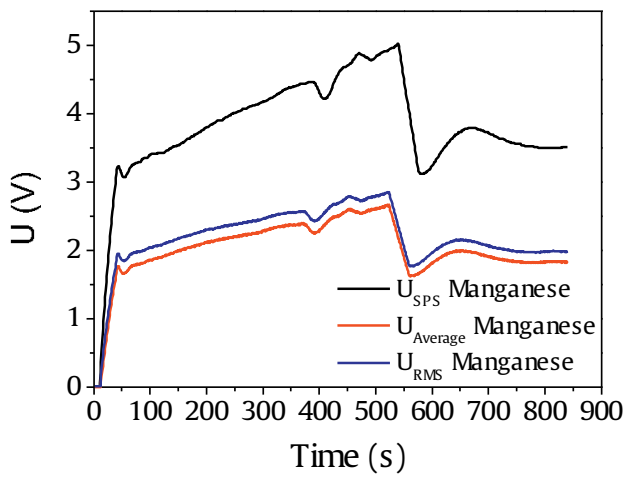

Fig. 2. Measurements of intensities ( $a$ and $b$ ) and voltage values ( $c$ and d) for alumina ( $a$ and $c$ ) and manganese ( $b$ and d) called $I_{\text {SPS }}$ and $U_{S P S}$, the mean values $I_{\text {average }}$ and $\mathrm{U}_{\text {average }}$ and RMS values $\mathrm{I}_{\mathrm{RMS}}$ and $\mathrm{U}_{\mathrm{RMS}}$.

the level of the Inconel parts. Anyway, the discrepancy between the two temperatures remains of the order of several degrees Celsius.

From the electric measurements, several trends are observed: (i) the variations of the RMS voltage and intensity (Fig. 2) during the thermal cycle are similar in both cases (conducting or non-conducting materials); (ii) for both materials the voltages and intensities at the dwell temperature (at about 540 s, after the

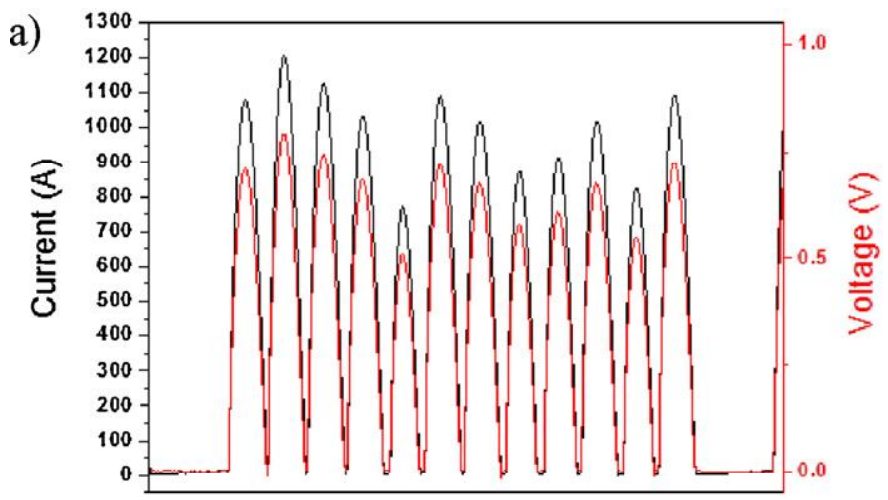

Time

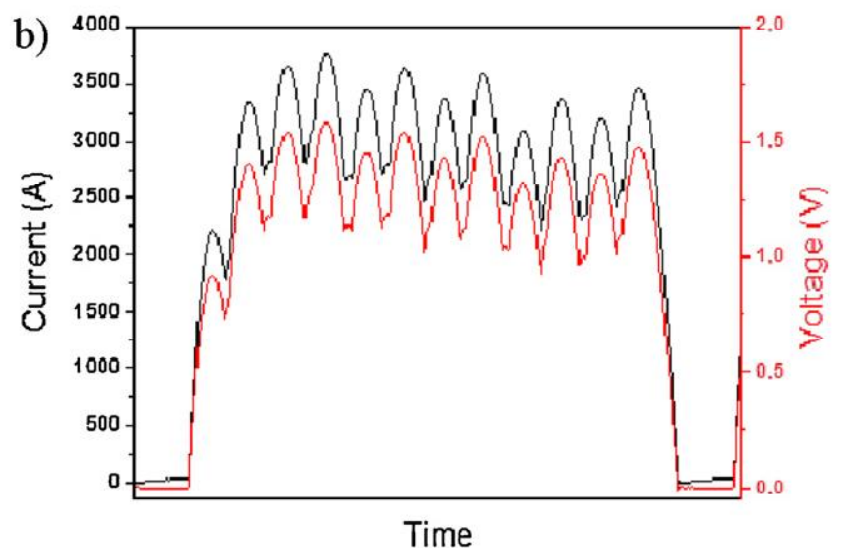

Fig. 3. Superposition of current and voltage signals: (a) beginning of the cycle and (b) end of cycle.

sudden decrease from $510 \mathrm{~s}$ ) are not constant, firstly increasing and then decreasing slowly with time.

The electrical measurements show, both for conducting and insulating materials, strong differences especially for the voltage signal between the values given by the SPS machine software and the values calculated from the recordings (Fig. 2). These can be explained by the fact that for the $U_{S P S}$ voltage measurement, the sensor is located just outside the power source far from the graphite column. Therefore, the voltage values given by the SPS machine can be considered over-estimated because the voltage drop associated with the resistance of copper conductors, the water-cooling jacket and the Iconel ram cover placed between the generator and the of SPS column is not taken into account.The purely resistive character of the stack (column + tool + sample) was also wanted verified. According to the assumptions of Orrù et al. (2009) concerning the electrical phenomena brought into play during SPS sintering, the voltage across the device $(\mathrm{u}(\mathrm{t}))$ is composed of the voltage corresponding to Joule heating $\mathrm{u}_{\mathrm{R}}(\mathrm{t})$ to which should be added if any the voltage of the voltage of the inductor system $u_{L}(t)$, due to rapid changes in pulse intensity (3):

$\mathrm{u}(\mathrm{t})=\mathrm{u}_{\mathrm{R}}(\mathrm{t})+\mathrm{u}_{\mathrm{L}}(\mathrm{t})=\operatorname{Ri}(\mathrm{t})+\mathrm{L} \frac{\mathrm{di}(\mathrm{t})}{\mathrm{dt}}$

The presence of an inductor component in the electrical description of SPS would involve a phase shift between voltage and intensity. Therefore, the voltage across a graphite die containing alumina and the current in the circuit were recorded with a sampling frequency of $10,000 \mathrm{~Hz}$, (Fig. 1). Records of voltage and current at two moments of the thermal cycle show that the curves representing $\mathrm{u}(\mathrm{t})$ and $\mathrm{i}(\mathrm{t})$ are superimposed on a scale factor (Fig. 3). This suggests that there is no phase shift between these two values 
Table 1

Properties of inconel and graphite (with T in Kelvin).

\begin{tabular}{|c|c|c|c|c|}
\hline & Unit & Inconel 600 & Graphite (Molénat e & t al., 2010) \\
\hline Heat capacity & $\mathrm{C}_{\mathrm{p}}\left(\mathrm{Jkg}{ }^{1} \mathrm{~K}^{1}\right)$ & $\begin{array}{l}344+2.5010^{1} \mathrm{~T} \\
\text { Conrad et al. }(1990)\end{array}$ & $34.27+2.72 \mathrm{~T}-9.6$ & $10^{4} \mathrm{~T}^{2}$ \\
\hline Thermal conductivity & $\lambda\left(\mathrm{Wm} \mathrm{m}^{1} \mathrm{~K}^{1}\right)$ & $\begin{array}{l}10.09+1.57 \quad 10^{2} \mathrm{~T} \\
\text { (www.hightempmetals.com) }\end{array}$ & $0.06 \mathrm{~T}+2.58$ & $10^{5} \mathrm{~T}^{2}$ \\
\hline Electrical resistivity & $\rho_{\mathrm{e}}(\Omega \mathrm{m})$ & $\begin{array}{l}9.8210^{7}+1.6 \quad 10^{10} \mathrm{~T} \\
\text { (www.hightempmetals.com) }\end{array}$ & $\begin{array}{l}2.14 \quad 10^{5} \text { to } 1.34 \\
+4.42 \quad 10^{12} \mathrm{~T}^{2}\end{array}$ & $10^{8} \mathrm{~T}$ \\
\hline Density & $\rho\left(\mathrm{kg} \mathrm{m}^{3}\right)$ & 8430 (www.hightempmetals.com) & $0.01414 \mathrm{~T}$ & \\
\hline
\end{tabular}

which in turn implies that the column of the device has no reactive component. This proves that from an electrical point of view, the stack, the core of the system, has a purely resistive behavior. As a consequence, the heating power produced by the Joule effect can be calculated from the expressions $\mathrm{P}=\mathrm{UI}, \mathrm{P}=\mathrm{RI}^{2}$ or $\mathrm{P}=\mathrm{U}^{2} / \mathrm{R}$.

The instrumental data reported above is the basis for the improvement of the previous numerical model developed by Molénat et al. (2010) using the finite element method for electrothermal modeling of the SPS device.

\section{Modeling}

\subsection{Definitions}

In prior work, the geometry and the optimized mesh of the device (Fig. 1) as well as the physical operations (including various laws and the physical constants) relative to its heating by Joule effect have already been defined (Molénat et al., 2010).

\subsubsection{Material characteristics}

The stack considered was composed of Inconel elements and a column, consisting of several different graphite pieces (spacers, punches and a die). The various elements of this stack were assumed to be isotropic, which has the effect of considering all the physical properties uniform in all directions. The different properties of the Inconel and graphite used are given below in Table 1. The SPS numerical models were performed on two samples with different electrical properties, alumina as insulator and manganese as conductor (www.matweb.com). Their main physical properties are given in Table 2.

Some more approximations or hypothesis have been considered - the uniaxial pressure is considered as constant over the whole cycle; samples are considered fully dense; geometrical variations are considered inexistent over the whole cycle. The paper sheet (Mersen, Papyex ) usually placed on the inner wall of the die is not taken into consideration in the element geometry but is assimilated to the adjacent graphite block.

\subsubsection{Physics used in the models}

During the SPS process, the thermoelectric coupling results from Joule heating. The laws used in this study concern the conservation of thermal energy (heat transfer by conduction, radiative losses) and electrical power. The coupled conservation equations used at

Table 2

Properties of samples: alumina and manganese (with T in Kelvin).

\begin{tabular}{|c|c|c|c|}
\hline & Unit & Alumina & Manganese \\
\hline Heat capacity & $C_{p}\left(J k g{ }^{1} K^{1}\right)$ & 850 & 480 \\
\hline $\begin{array}{l}\text { Thermal } \\
\text { conductivity }\end{array}$ & $\lambda\left(\mathrm{W} \mathrm{m}{ }^{1} \mathrm{~K}^{1}\right)$ & $39,500 \mathrm{~T} 1.26$ & $7.68+0.0056 \mathrm{~T}$ \\
\hline $\begin{array}{l}\text { Electrical } \\
\text { resistivity }\end{array}$ & $\rho_{\mathrm{e}}(\Omega \mathrm{m})$ & $8.7 \quad 10^{19} \mathrm{~T} 4.82$ & $\begin{array}{cccc}1.43 & 10^{6}+4 & 10 & 10 \\
3 & 10^{13} \mathrm{~T}^{2} & \end{array}$ \\
\hline Density & $\rho\left(\mathrm{kg} \mathrm{m}^{3}\right)$ & 3899 & 7440 \\
\hline
\end{tabular}

each point of the solids and each time step $t$ are the power equation (4) and the heat equation (5). The physical properties of the materials, such as electrical conductivity, thermal conductivity and heat capacity are, in addition, considered as thermally dependent.

$\nabla \cdot(\nabla \mathrm{U})=0$

$\nabla \cdot(\lambda \nabla \mathrm{T})+\rho C_{\mathrm{p}}\left(\frac{\partial T}{\partial t}\right)=\sigma(\nabla \mathrm{U})^{2}$

$U$ is the electric potential, $T$ the temperature, $\lambda$ the thermal conductivity of the material, $\rho$ the density, Cp the heat capacity and $\sigma$ the electrical conductivity.

\subsubsection{Limit condition used in the models}

Both electrical and thermal limit conditions have to be defined for the modeling of our SPS device.

Owing to the characteristics of the underlying physics (Joule effect) and thus to the FEM calculations that should be performed to describe the behavior of the SPS column, the thermal and electrical limits introduced as the inputs of the model must necessarily be considered at the same level of the column. For the stack, the thermal limit conditions are known at the edge of the water cooling system. Therefore, the RMS voltage values to be introduced as the limit conditions must be considered on the same surface. However, for voltage measurements, the electrodes can only be positioned between the Inconel parts and large graphite spacers (Fig. 1). Thus, it will be necessary to apply a correction factor to the voltage measurements in order to get that across the Inconel parts. This correction factor has been estimated at 1.01. For all models (alumina, manganese, etc.) the voltage values calculated by the model at the Inconel/graphite border were compared to the experimental RMS voltage. A very good agreement between experimental and calculated values was observed over the entire thermal cycle validating this corrective factor.

It is important to note that the hypothesis that the voltage is uniformly distributed across the device (Inconel part, graphite spacer etc.) has been made. This was post-validated, verifying that the voltage variations between the center and the outside surface of the electrode located between the Inconel part and large spacers were modeled to within a few $\mathrm{mV}$. This uniform voltage distribution of course does not take into account a possible skin effect. Modeling with skin effect is easily possible for both the voltage across the tool, and for the whole column. According to the work published by of Anselmi-Tamburini et al. (2005), it seems that, owing to the low frequency $(300 \mathrm{~Hz})$ of the current, a skin effect can be ignored with regard to the dimensions of the geometry studied.

As the experiments were carried out under vacuum, heat loss corresponding from the lateral surfaces of the device are considered as radiative only and expressed by the the heat flux ( $\mathrm{r}$ formula (6):

$\Phi_{\mathrm{r}}=\sigma_{\mathrm{s}} \cdot \varepsilon \cdot\left(\mathrm{T}_{\mathrm{e}}^{4} \mathrm{~T}_{\mathrm{a}}^{4}\right)$

where $\sigma_{\mathrm{s}}$ is the Stefan-Boltzmann constant $5.670410^{8} \mathrm{Wm}^{2} \mathrm{~K}^{4}$, ( the emissivity of material, in our 
case $\left(=0.8\right.$ for the graphite, $T_{e}$ the surface temperature of the graphite die and $\mathrm{T}_{\mathrm{a}}$ the chamber temperature.

Considering the horizontal symmetry of the stack, it was assumed that the radiation losses of the horizontal sides are absorbed by the opposing sides-as a consequence they cancel out. Heat losses by radiation are considered only on the vertical cylindrical walls.

A system of water cooling removes some heat at the electrodes toward the Inconel steel. The equation of conducto-convective heat flow $\Phi_{\mathrm{c}}$ is expressed by (7):

$\Phi_{\mathrm{c}}=\mathrm{h}_{\mathrm{c}}\left(\mathrm{T}_{\mathrm{i}} \quad \mathrm{T}_{\mathrm{w}}\right)$

where $h_{c}$ is the conducto-convective coefficient, $T_{i}$ the water temperature and $\mathrm{T}_{\mathrm{w}}$ the temperature of the wall in contact with water.

According to the work of Vanmeensel et al. (2005), the coefficient $h_{c}$ is $880 \mathrm{Wm}{ }^{2} \mathrm{~K}$. Note that the water cooling circuit which operates directly on all the Inconel steel surfaces was considered with water at $27^{\circ} \mathrm{C}$, while in the experimental setup this is achieved by a steel piece containing the cooling system.

The sides of all equipment are considered as electrically insulated, but, while in the publication of Molénat et al. (2010), a constant voltage was imposed at the top of the device. Here, a more realistic SPS experiment was modeled using on the top, the RMS voltage derived from the measurements. The RMS voltage is a function of time, it takes into account variations of potential during heat treatment.

All elements of the stack are considered in union, which means that a thermal and electrical continuity was considered between each element. Anselmi-Tamburini et al. (2005) stated that an applied pressure above $50 \mathrm{MPa}$ was used to minimize the contact resistances. Therefore they are ignored in the present simulations as a pressure of $100 \mathrm{MPa}$ is applied since room temperature and during the overall sintering cycle.

All the elements of the stack are considered to present thermal and electrical continuity between each other. Anselmi-Tamburini et al. (2005) stated that an applied pressure above 50 MPa was used to minimize contact resistance. Therefore they are ignored in the present simulations as a pressure of $100 \mathrm{MPa}$ was applied since room temperature and during the whole sintering cycle. Some more approximations or hypothesis have been considered: - the uniaxial pressure is considered as constant over the whole cycle; samples are considered fully dense; geometrical variations are considered inexistent over the whole cycle. The paper sheet(Mersen, Papyex ) usually placed on the inner wall of the die is not taken into consideration in the element geometry but is assimilated to the adjacent graphite block.

\subsubsection{Solution procedure for the numerical model}

The finite element method (FEM), based on the Ritz method, is used to numerically solve, with a single approximation of unknown field, problems involving partial differential equations. In addition, the FEM commercial software used (COMSOL Multiphysics) allows the numerical resolution of coupled differential equations. The physical space studied is divided into elementary zones, named elements, with multiple nodes on which the variables of the problem are defined (temperature, current, voltage...): this define the mesh of the system. On each element, interpolation functions perform approximations of scalar or vector fields. The quality of the approximation given by numerical solution depends on the size and shape of the mesh. A tetrahedral mesh, less efficient than a quadratic, but easier in use has been preferred. Molénat et al. (2010) have determined an optimum size of the mesh elements for this type of device to ensure a minimum error in the calculations.

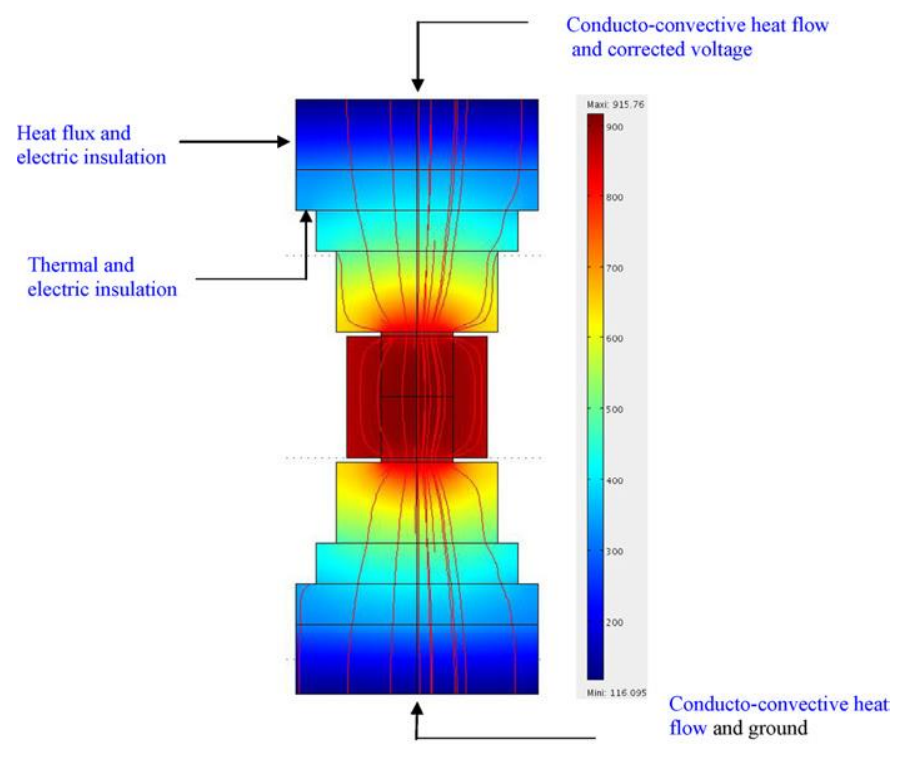

Fig. 4. Vertical section with no sample at $\mathrm{t}=540 \mathrm{~s}$ : temperature map $\left({ }^{\circ} \mathrm{C}\right)$ and streamlines extracted from model M1 without sample (red lines represent the current lines). (For interpretation of the references to color in the text, the reader is referred to the web version of this article.)

\subsection{Results and discussion}

\subsubsection{Standard modeling}

The results for modeling (M1) the three standard experiments respectively with no sample, with manganese and with alumina samples are given below. In all three cases similar temperature gradients are observed in the SPS columns but not to burden the text only one is drawn (Fig. 4).

3.2.1.1. No sample. The system without a sample is first considered to compare the temperatures extracted from the model (Fig. 4) with those measured experimentally. During the isothermal dwell for $\mathrm{T} 1$, a constant temperature difference between modeling and experiment was observed; the temperature resulting from the model is $35^{\circ} \mathrm{C}$ lower than the measurement.

Similarly, when modeled RMS current intensities are compared to RMS currents (not shown), a curve with the same shape was found, but the modeled values were lower than the measured values. This is probably linked to the fact that the leaves of Papyex inserted between the Inconel and graphite spacer were not taken into account in the modeling. Indeed, Anselmi-Tamburini et al. showed that the addition of leaves Papyex caused a large change in current through the device.

3.2.1.2. With a sample of manganese. For the simulation with the manganese sample, a very good agreement between calculated temperatures and those measured by the T1thermocouple located $3 \mathrm{~mm}$ beneath the surface of the tool is observed (Fig. 5). It should be noted that on the dwell, the temperature measured by the thermocouple remains constant while that provided by the model tends to decrease owing to the voltage decrease previously observed.

Now, the temperature evolution at the level of the graphite spacers should be compared (Fig. $6 a$ and b). In addition to the temperature difference between the upper and lower spacers linked to a slight asymmetry of the system which have been previously discussed, it is important to note the significant difference in temperature between the measured and calculated values. This difference increases with dwell time and distance from the tool. It is to be noted that the simulated temperature of the small spacer (T2, T3) seems stable during the dwell time while the measured value 


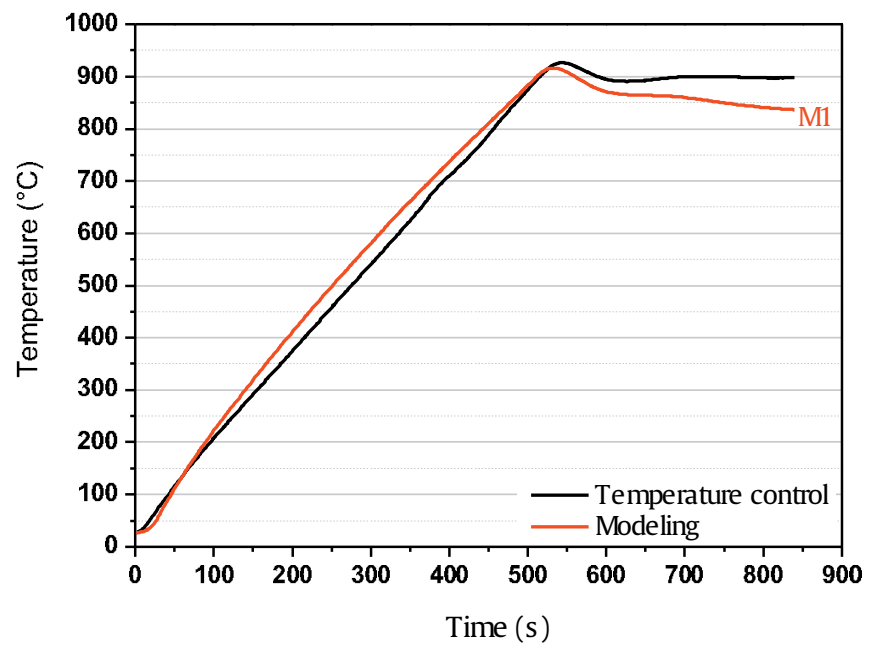

Fig. 5. Temperatures on the graphite die for manganese sample (at temperature control point T1- Fig. 1): recording (black) and modeling (M1 - red). (For interpretation of the references to color in the text, the reader is referred to the web version of this article.)
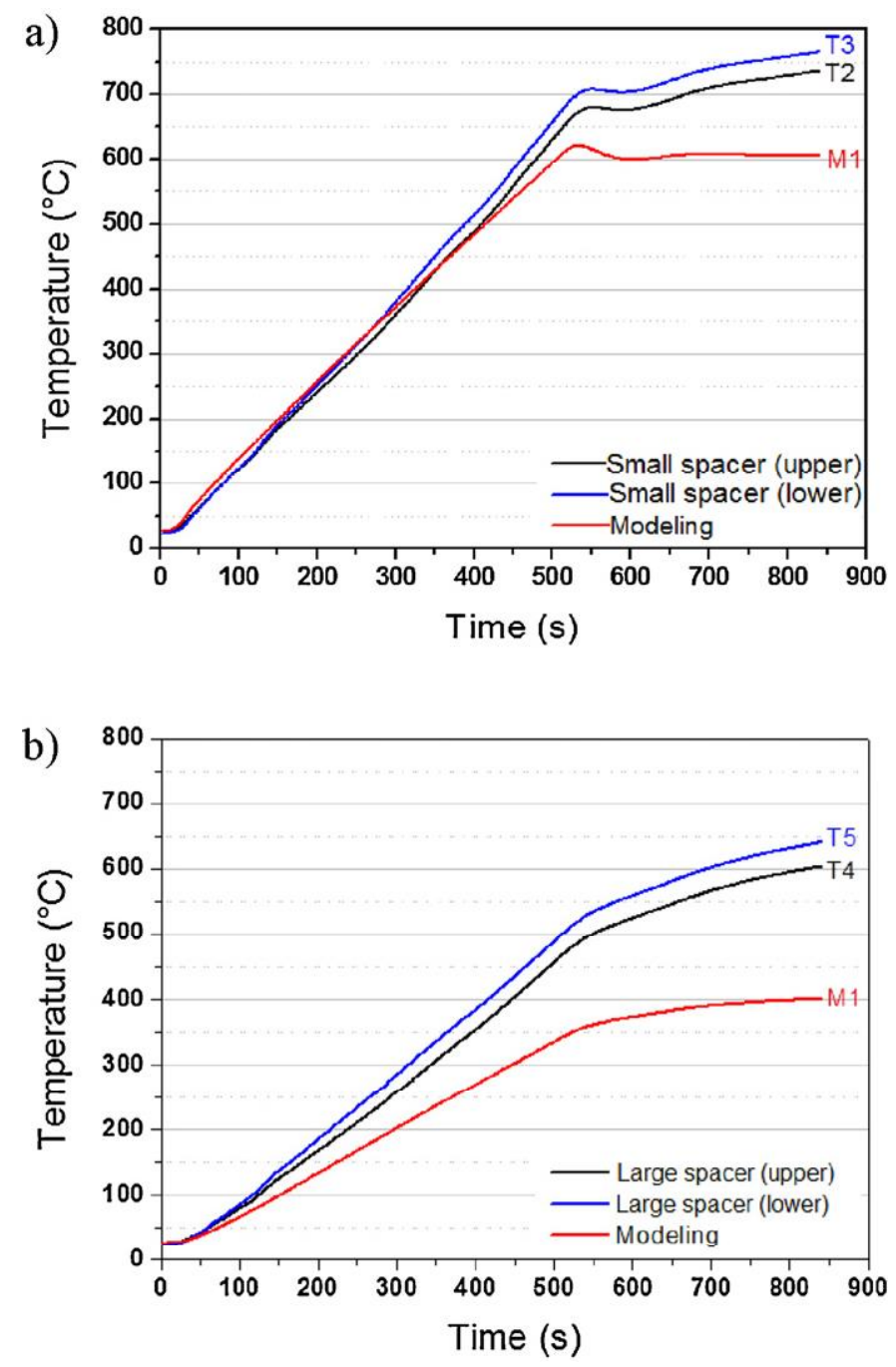

Fig. 6. Temperatures of (a) small spacers (T2, T3) and (b) large spacers (T4, T5) for manganese sample: modeling (M1 - red) and recording (up = black and down = blue). (For interpretation of the references to color in the text, the reader is referred to the web version of this article.)
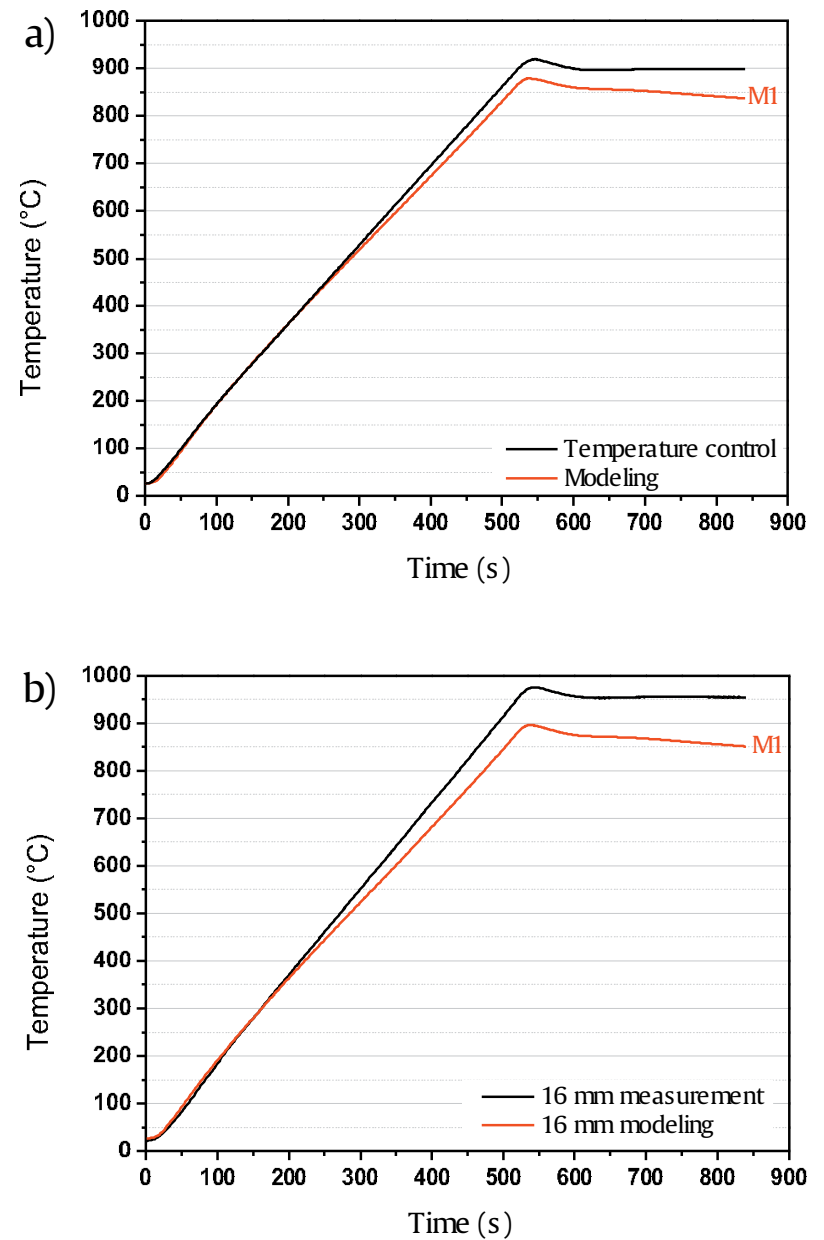

Fig. 7. Modeled (M1) and measured temperatures at the alumina sample (T1) (a) $3 \mathrm{~mm}$ from the surface (b) $16 \mathrm{~mm}$ from the surface.

increases monotonically. For the large spacers $(\mathrm{T} 4, \mathrm{~T} 5)$ the measured and simulated temperatures increase during the dwell time. The differences between the measured and simulated spacer temperatures come from a likely overestimation of heat transfer along the column from the tool to the Inconel parts.

3.2.1.3. With a sample of alumina. For the simulation with alumina a good agreement is observed at the beginning of the temperature ramp between the calculated temperature and that measured with the T1 thermocouple. Unlike the observations made with manganese, above $400^{\circ} \mathrm{C}$ measured and calculated temperatures differ to reach a gap of nearly $75^{\circ} \mathrm{C}$ at the dwell temperature. As for manganese, differences and similar trends are observed between the measured and calculated temperatures of the spacers. Considering now the temperature of the graphite die, the simulation confirms the thermal gradient observed inside the wall of the die. Indeed, in both cases (measured and calculated) the temperature near the inner wall (Fig. 7b) is higher compared to the one at the surface (Fig. 7a). However, the temperature distribution in the die given by the model does not seem to be consistent with reality as the measured gradient is steeper than the calculated one. This discrepancy can potentially be explained by an inhomogeneous current distribution in the wall of the matrix as suggested by Anselmi-Tamburini et al. (2005) or by the fact that the contribution of the graphite sheet was not taken into account in the modeling.

The M1 model correctly describes the temperatures measured by the SPS T1thermocouple for the three standard experiments. Indeed, the general shape of the experimental temperature ramp 


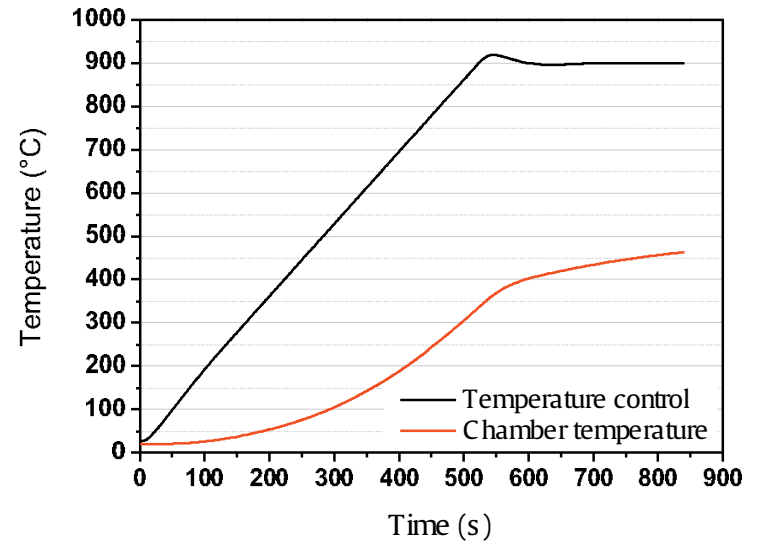

Fig. 8. Experimental temperatures of the die (T1).

is well reproduced by the simulation: the ramps fit relatively well, the differences between measurements and modeling in the early stages $\mathrm{t}=540 \mathrm{~s}$ are moderated about $44^{\circ} \mathrm{C}$ for graphite (case without sample), $10^{\circ} \mathrm{C}$ for manganese and $40^{\circ} \mathrm{C}$ for alumina. However, the temperatures modeled at the dwell for both manganese and alumina are not constant, as they were in the experimental data.

When comparing the temperatures given by the model at $\mathrm{t}=700 \mathrm{~s}$ according to the radial position on the sample, it is found that the alumina sample has a quasi-uniform temperature with a variation of the order of $0.5^{\circ} \mathrm{C}$ (its center being slightly colder than the periphery), while the manganese sample has a temperature difference of about $15^{\circ} \mathrm{C}$ between its periphery (colder) and its center. When the temperature gradient in the die is observed, it is found that decreases in temperature between the inner and outer surfaces are almost identical for the three different models: $24^{\circ} \mathrm{C}$ for graphite, $22^{\circ} \mathrm{C}$ for manganese and $20^{\circ} \mathrm{C}$ for alumina. In the simulation performed with a sample, either manganese or alumina, comparing the measured and calculated temperatures at several points of the SPS column, the temperature gap is found to be minimum in the die at the level of the sample compared to those observed on the spacers. This suggests that heat transfers from the Inconel parts to the cooling water are actually lower than those considered in the model. In addition, when the temperatures at different times of the cycle are compared, including the start and end of dwell, it is found that the differences between measurements and modeling increase regardless of the nature of the sample and the point of the device studied. The influence of tool radiation to the chamber can be discussed in particular when large dies are employed. The influence at high temperature of the chamber and the stainless steel walls around our system is not fully taken into account and could explain the decrease in the modeled temperature of the device during the dwell step. Indeed during these standard tests, the temperature of the chamber was also recorded (in the vicinity of the stainless steel walls) and was found that it does not remain at $27^{\circ} \mathrm{C}$ throughout the cycle but increases steadily (Fig. 8) and reaches almost $460^{\circ} \mathrm{C}$ at the end of $5 \mathrm{~min}$ of the dwell. Therefore, it can be considered that the heat loss of the device decreases as the temperature of the chamber increases. This has the effect of reducing the energy required to maintain the device at the setpoint temperature. Therefore, the temperature chamber was introduced as an input variable in our model (M2). Of course, depending on its emissivity $(\varepsilon)$ the radiation of the chamber should be considered, whether it is hot or cold, but for convenience it is easier to consider the chamber as black body with known temperature rather than an imperfect heat reflector with unknown emissivity.

Finally, when the RMS intensities calculated and delivered during these three types of tests are compared (not shown) it is found that the intensities modeled are always lower than those measured.

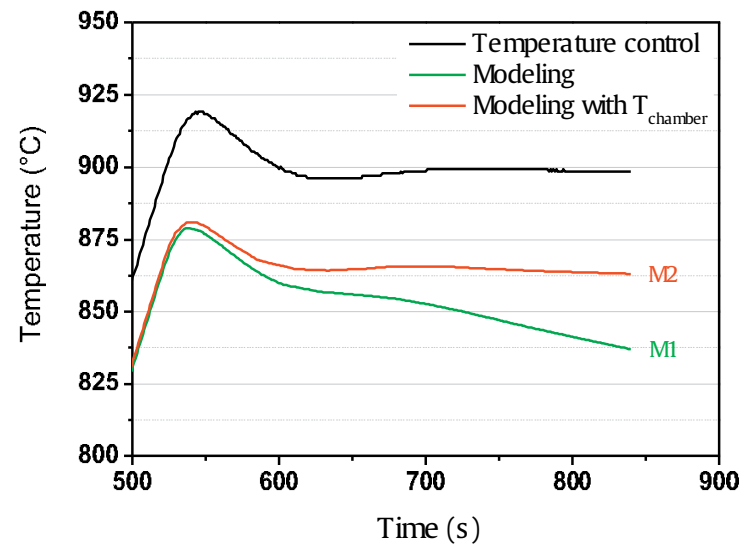

Fig. 9. SPS thermocouple temperatures (T1) on the dwell for the chamber during the experiment with the alumina sample alumina sample: modeled (M2 - red) and measured (black). (For interpretation of the references to color in the text, the reader is referred to the web version of this article.)

The greatest difference is observed for the system without a sample, the situation for which the largest differences in temperature were already observed. The measured RMS Voltage was used as a limiting condition in the present simulation. Therefore one would expect the model to give the same order of magnitude for the RMS intensities as the measured ones. This is not the case, so the graphite resistivity values introduced in our model could be challenged.

\subsection{Variation of chamber temperature}

A second simulation (M2) of the system containing alumina was performed taking into account the evolution of the temperature chamber reported in Fig. 8. This set of data was considered as limit conditions in the same way as the RMS values while in previous simulations the chamber temperature was considered stable and equal to $300 \mathrm{~K}$ during the overall sintering cycle.

The temperature modeled SPS for thermocouple T1 has the same evolution/ramp as the experimental measurements. On the dwell, the calculated temperature (Fig. 9) is now stable over this period due to the fact that heat loss at the vertical walls is reduced when the temperature in the chamber increases. These results confirm that when the tools are large, their radiation and consequently the chamber temperature have an obvious influence on the thermal description of the device. However, even if the temperature appears more stable, a difference remains between the measured and modeled values. This discrepancy may either be due to the values retained for the graphite properties, not taking into account the contribution of the thermal and electrical contact resistances or the graphite paper sheet (Papyex ) or as mention previously to the fact that too high levels of Inconel/water exchange by conduction-convection was considered as leading to over-estimation of the heat transfer.

At dwell, looking at the small spacers (T2, T3) (Fig. 10) it is found that the temperature of the chamber also has an influence on their temperature. Although the calculated values are still far from the measured ones, its general tendency on the overall SPS cycle is now closer to that of the measurements. Similar observations were made for the large spacers (T4, T5).

Taking into account the variation of the temperature chamber or not has no effect on the calculated current intensity.

In conclusion, the modeled temperatures (M2) are closer to the experimental values when taking into account the temperature variation of the chamber during the SPS cycle while calculated intensities of the current are identical in both models. The calculated values of the current are mainly influenced by the resistivity 


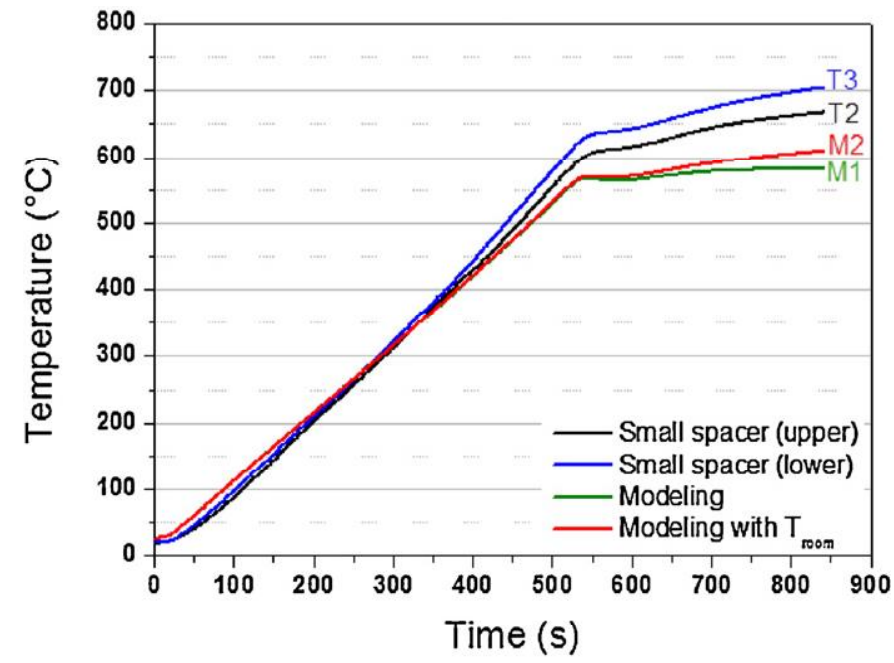

Fig. 10. Temperatures of small spacers for alumina sample: modeling (M2 - red) and recording (T2 black, T3 blue). (For interpretation of the references to color in the text, the reader is referred to the web version of this article.)

of the entire system. It is therefore important to study the influence of the properties of graphite on the modeling results (M3).

\subsection{Influence of graphite properties}

Noting the differences in RMS intensity values between measurements and modeling, it was concluded that the resistivity of the graphite used in the model should be different from our experimental setup. The graphite supplier provided the temperature evolution of the properties of the graphite (Mersen, ref. 2333) used to manufacture the entire stack (spacers, punches and dies). One should keep in mind that these are average values and may vary slightly from one batch to another. For the electrical resistivity (Fig. 11), it was found that the values of the material were lower than those commonly reported in the literature for graphite and originally considered in the previous simulations (Molénat et al., 2010).

The heat capacity values (from the literature) used in the first model (M1) are slightly different from those of the material provided in the temperature range studied here (300-1400 K). As a consequence, changing from one to another should not have greatly influenced the results. Considering the thermal conductivity, from room temperature to $1600^{\circ} \mathrm{C}$, the values for the graphite grade used are significantly higher than those found in literature (Fig. 12). This

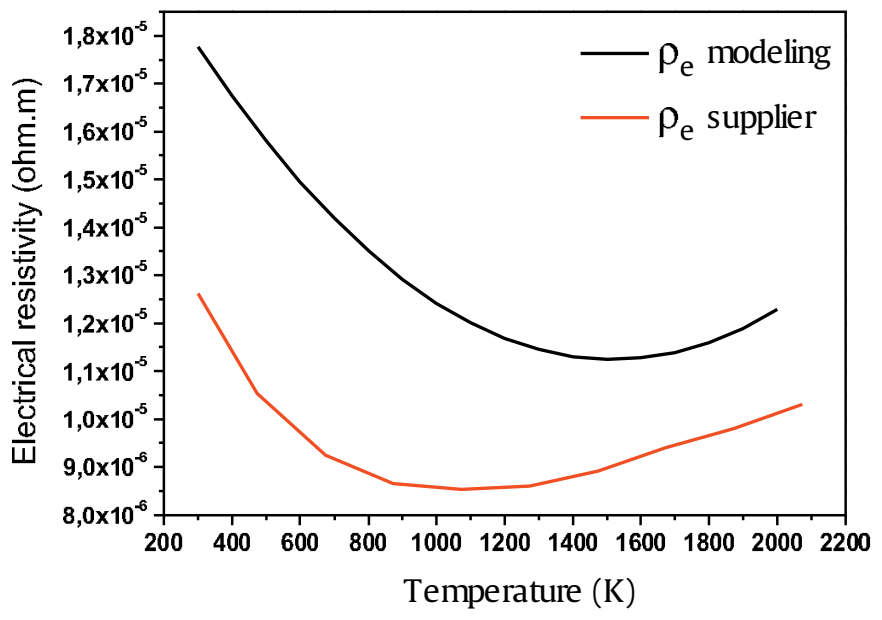

Fig. 11. Electrical resistivity of graphite.

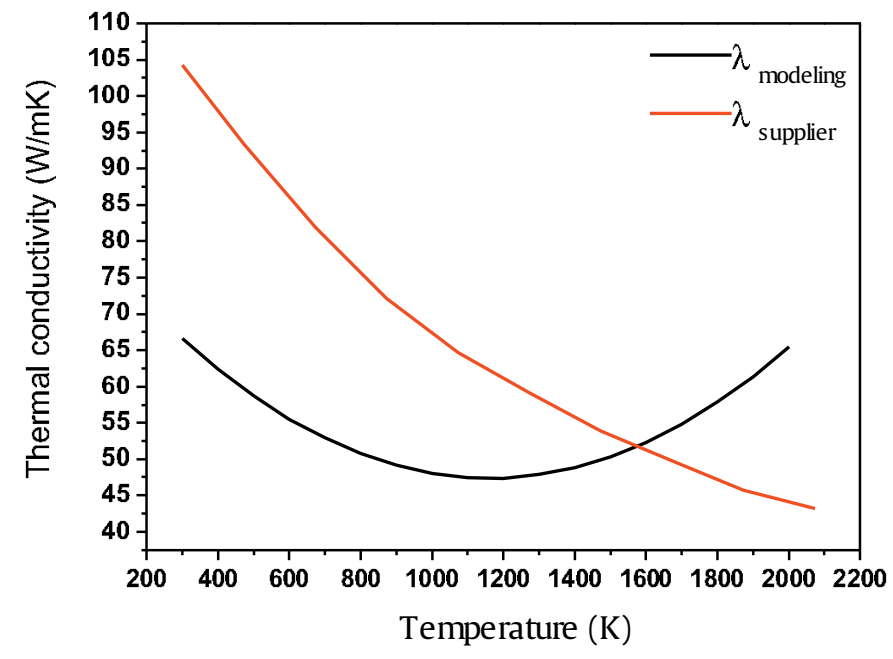

Fig. 12. Thermal conductivity of graphite: modeling (black) and supplier(red) modeling (black) and supplier (red). (For interpretation of the references to color in the text, the reader is referred to the web version of this article.)

leads to better heat transfer from the warmer to the cooler parts which contribute to homogenizing the temperature inthe graphite column.

The system containing an alumina sample have been simulated changing all the graphite properties from those taken from the literature to those given by the manufacturer (M3). For simplicity, the chamber temperature was considered constant at $300 \mathrm{~K}$.

The calculated T1 temperature curve (M3) does not follow the measured one at all-it is always higher both during the ramp and the dwell.

The temperatures modeled for the small spacers (T2, T3) are found to be higher than the measured values (Fig. 13). However for the large spacers (T4, T5), the values were closer to the measured values during the ramp and the dwell (Fig. 14). With the supplier's values, the temperature differences between experiment and model are smaller than with the first model M1. However, it must be remembered that at all points, and particularly on the die, the temperatures were well above the measured values.

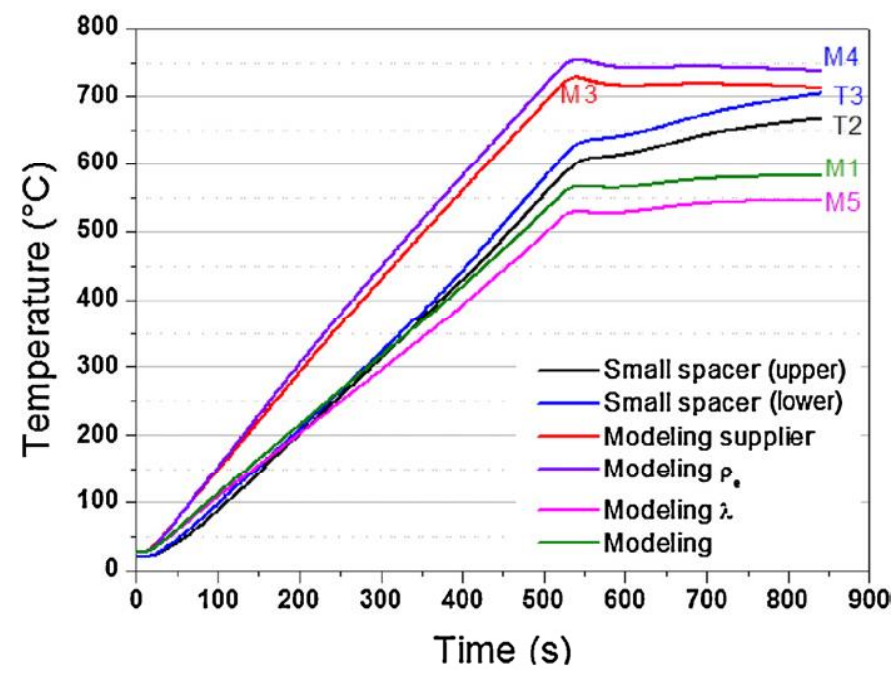

Fig. 13. Comparison of surface temperature (T1) for the alumina sample: measured (black), modeling supplier (M3 - red), modeling $\rho_{\mathrm{e}}$ (M4 - purple), modeling $\lambda$ (M5 - pink), the first model (M1 - green). (For interpretation of the references to color in the text, the reader is referred to the web version of this article.) 

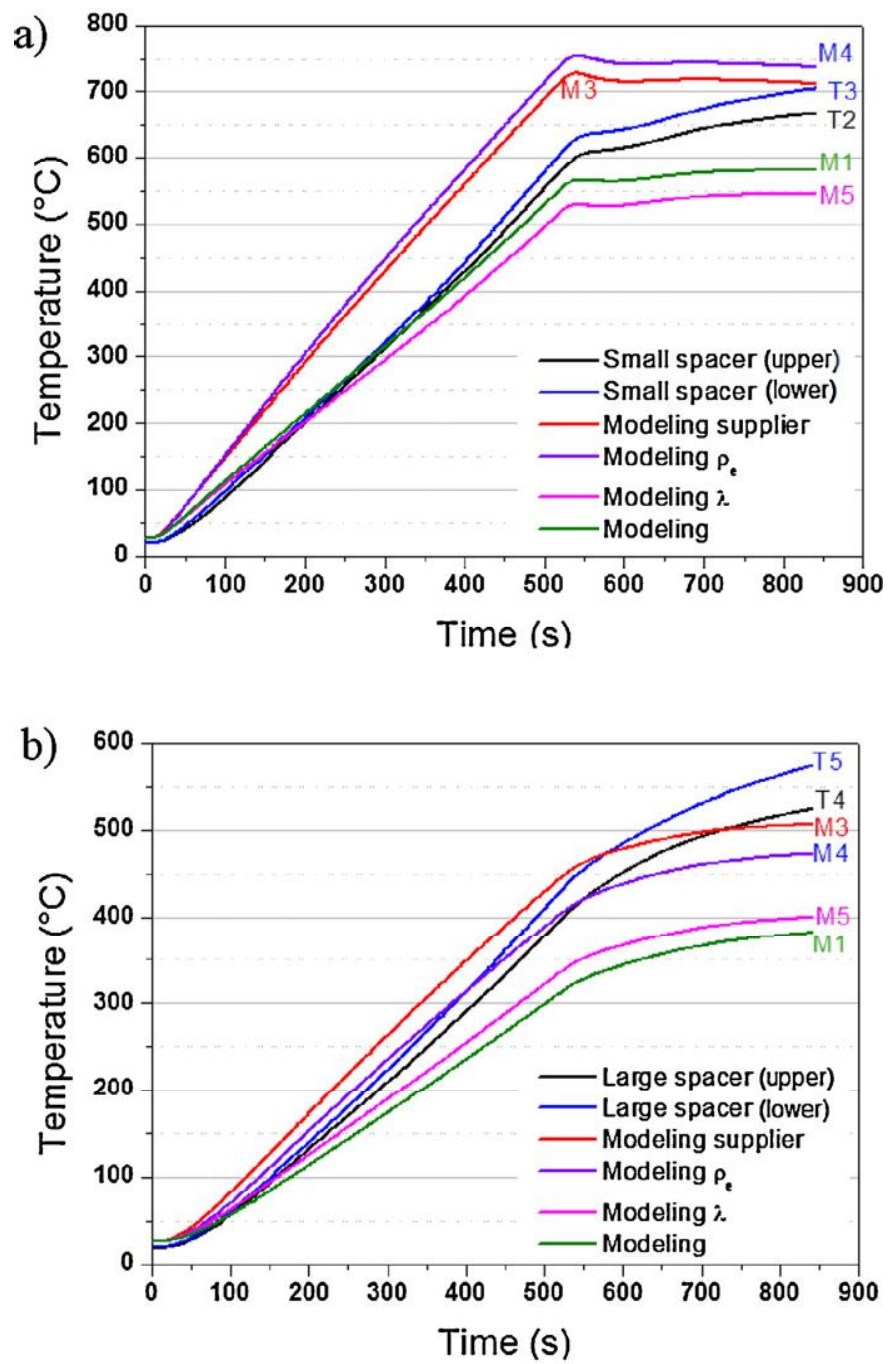

Fig. 14. Comparison of the temperature on a) small spacers $(\mathrm{T} 2, \mathrm{~T} 3)$ and $\mathrm{b})$ the large spacer (T4, T5) for alumina sample: measured (black/blue), modeling supplier's values (M3 - red) modeling $\rho_{\mathrm{e}}(\mathrm{M} 4$ - purple), modeling $\lambda$ (M5 - pink), the first model (M1 - green). (For interpretation of the references to color in the text, the reader is referred to the web version of this article.)

In order to define the influence of each parameter two calculations were done:

- The first, $\rho_{\mathrm{e}}$, concerns the influence of the electrical resistivity of the graphite: all physical parameters of the initial model $(\varepsilon, \lambda, \mathrm{Cp}$ and $\rho$ ) were kept, only the electrical resistivity was modified to the values given by the supplier. This calculation was named M4. - The second, $\lambda$, concerns the influence of the thermal conductivity of graphite: all physical parameters of the initial model $\left(\varepsilon, \rho_{\mathrm{e}}, \mathrm{Cp}\right.$ and $\rho$ ) were kept only the thermal conductivity was modified to the values given by the supplier. This calculation was named M5.

As mentioned previously, considering the small difference of heat capacities (literature and supplier) over the temperature range investigated, the influence of this parameter was not studied.

All the temperature variations are reported in Figs. 13 and 14. It may be noted that the small decrease in the graphite electrical resistivity significantly increases the value of the modeled temperature of the die and the spacers (M4). However, the significant increase in the thermal conductivity only causes a small decrease in the temperature of the die and small spacers while it causes a larger increase in temperature for the large spacer (M5). The column

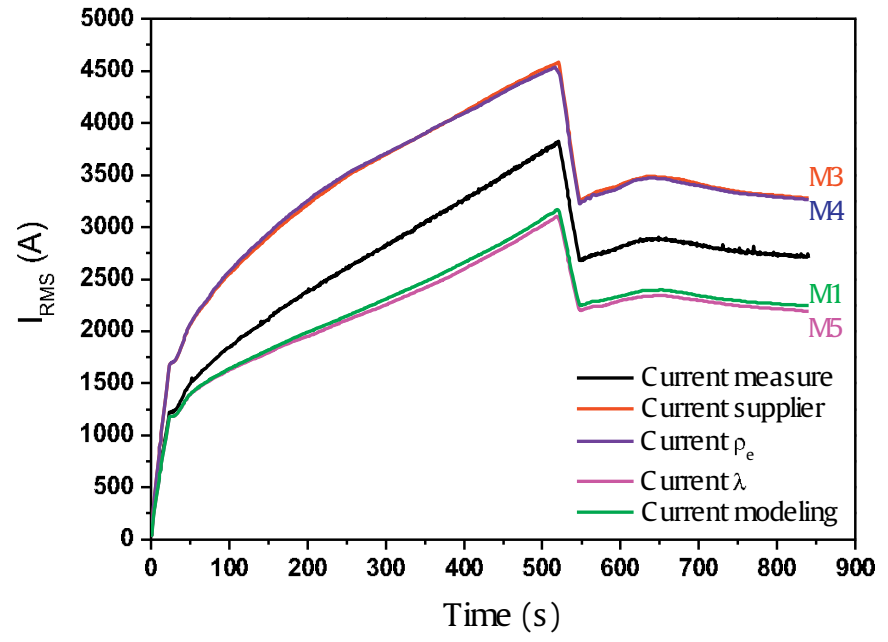

Fig. 15. Comparison of RMS current modeled for alumina sample: measured (black), modeling supplier (M3 - red), modeling $\rho_{\mathrm{e}}$ (M4 - purple), modeling $\lambda$ (M5 - pink), the first model (M1 - green). (For interpretation of the references to color in the text, the reader is referred to the web version of this article.)

temperature tends to homogenize. To validate the model particularly modifying the graphite properties, the calculated RMS current should be now compared to the measured values. As mentioned above, it can be seen in Fig. 15 that the RMS current intensity modeled in M1 (green curve) is significantly lower than that measured (black curve). However, when taking into account the parameters (electrical resistivity and thermal conductivity) provided by the graphite supplier, the calculated intensity (M3 - red curve) is much higher than measured. When the influence of the properties of graphite is studied, it is found that the electrical resistivity (M4 - purple curve) impacts the modeled current more strongly than the thermal conductivity (M5 - pink curve). A small change in electrical resistivity greatly affects the modeled current which consequently has a strong effect on the system temperature by Joule heating (the current being squared in the resistive heating equation). On the other hand, the change in thermal conductivity has a little influence on the modeled current (M5 - pink curve), similar current values are found compared with the first model (M1 green curve). (For interpretation of the references to color in the text, the reader is referred to the web version of this article.)

The differences between measurements and modeling results indicate that the graphite properties $\rho_{\mathrm{e}}$ and $\lambda$ (supplier and literature) do not match with the graphite properties in our experiments. The graphite parts are submitted to various thermal cycles which may cause aging and thus change their initial properties. Furthermore, Frei et al. (2007) showed that intercalating an increasing number of Papyex sheets between the electrode and SPS stack can greatly the influence current flowing through the SPS column which indicates that its introduction induces significant change in the electrical resistances of the stack. Therefore, not taking the different electrical and thermal contact resistances into account in this model may also explain the differences between calculated and measured values.

Thus, according to these calculations, considering a purely resistive system following Ohm's law, it can be concluded that for the same values of voltage, the calculated current is very sensitive to the electrical resistivity of the material used for the graphite column. As this latter is mainly heated up by Joule effect this also involves significant changes in the temperature of the die. Therefore, it can be concluded that considering intermediate values for electrical resistivity and thermal conductivity compared to those from the literature and from the supplier could provide more realistic current and temperature values. Modeled temperatures are 
close to the experimental values, and the model could be made more realistic taking into account: the chamber temperature, the correct properties of graphite, the graphite sheet and electrical and thermal contact resistances (under evaluation).

\section{Conclusions}

Electrical and temperature measurements and numerical simulations were conducted to evaluate the behavior of the column during SPS tests.

No phase shift was observed between instantaneous voltage and intensity indicating that the SPS column has a purely resistive behavior.

The effective value of the voltage $\left(U_{R M S}\right)$ is much lower than the average value given by the machine itself.

The improved experimental data and more accurate values of the physical properties of the graphite used enabled a more accurate numerical modeling.

\section{Acknowledgement}

The SPS was performed at the Plateforme Nationale CNRS de Frittage-Flash (PNF2/CNRS, Toulouse).

\section{References}

Anselmi-Tamburini, U., Gennari, S., Garay, J.E., Munir, Z.A., 2005. Fundamenta investigations on the spark plasma sintering/synthesis process: II. Modeling o current and temperature distributions. Materials Science and Engineering: A 394, 139-148

Chaim, R., Levin, M., Shlayer, A., Estournes, C., 2008. Sintering and densification of nanocrystalline ceramic oxide powders: a review. Advances in Applied Ceramics 107, 159-169.

Cincotti, A., Locci, A.M., Orrù, R., Cao, G., 2007. Modeling of spark plasma sintering/synthesis apparatus temperature, current and strain distribution with no powders. AIChE Journal 53, 703-719.

Conrad, H., Sprecher, A.F., Cao, W.D., Lu, X.P., 1990. Electroplasticity, the effect of electricity on the mechanical properties of metals. JOM 42 28-33.

Frei, J.M., Anselmi-Tamburini, U., Munir, Z.A., 2007. Current effects on neck growth in the sintering of copper spheres to copper plates by the pulsed electric current method. Journal Applied Physics 101, 114914.

Molénat, G., Durand, L., Galy, J., Couret, A., 2010. Temperature control in spark plasma sintering: an FEM approach. Journal of Metallurgy, 1-9.

Munoz, S., Anselmi-Tamburini, U., 2010. Temperature and stress fields evolution during spark plasma sintering processes. Journal of Materials Science 45 6528-6539.

Orrù, R., Licheri, R., Locci, A.M., Cincotti, A., Cao, G., 2009. Consolidation/synthesis of materials by electric current activated/assisted sintering. Materials Science and Engineering R 63, 127-287.

Ray, W.F., Davis, R.M., 1999. High frequency improvements in wide bandwidth rogowski current transducers. In: Proceedings of the 16th IEEE Instrumentation and Measurement Technology Conference, EPE 99, Lausanne, Sept 1999.

Ray, W.F., 1999. A 4000 arms highly stable calibration current source. In: Proceedings of the 16th IEEE Instrumentation and Measurement Technology Conference, EPE 99, Lausanne, Sept. 1999.

Vanmeensel, K., Laptev, A., Hennicke, J., Vleugels, J., Van der Biest, O., 2005. Modeling of the temperature distribution during field assisted sintering. Acta Materialia $53,4379-4388$.

Wang, C., Cheng, L., Zhao, Z., 2010. FEM analysis of the temperature and stress distribution in spark plasma sintering: modeling and experimental validation. Computational Materials Science 49, 351-362. 